\title{
Preparation of Silica by Sol-Gel Method Using Formamide
}

\author{
R.F.S. Lenza*, W.L.Vasconcelos** \\ Federal University of Minas Gerais-Department of Metallurgical and Materials \\ Engineering, 30160-030 Belo Horizonte - MG, Brazil
}

Received: November 21, 2000; Revised: July 10, 2001

\begin{abstract}
In this work we obtained microporous and mesoporous silica gels by sol-gel processing. Tetraethylortosilicate (TEOS) was used as precursor. Nitric acid and hydrofluoric acid were used as catalysts. In order to study the affect of formamide as drying additive, we used a molar ratio alkoxide/formamide of $1 / 1$. The performance of formamide in obtaining crack-free gels was evaluated through monolithicity measurements. The structural evolution occurring in the interconnected network of the gels during thermal treatment was monitored by Fourier transform infrared spectroscopy (FTIR), shrinkage and density measurements and nitrogen gas sorption. We noted that in the presence of formamide, the Si-O-Si bonds are stronger and belong to a more cross-linked structure. The samples obtained in the presence of formamide have larger pore volume and its pore structure is in the range of mesoporosity. The samples obtained without additive are microporous. Formamide allowed the preparation of crack-free silica gels stabilized at high temperatures.
\end{abstract}

Keywords: sol-gel, silica, nanostructure, FTIR

\section{Introduction}

The sol-gel process has received much attention in materials research in the past years due to its unique advantages such as low temperature processing, high homogeneity of final products and its capability to generate materials with controlled surface properties and pore structures between $1 \mathrm{~nm}$ and $500 \mathrm{~nm}^{1-4}$. These materials with tailored properties are especially adequate for using as matrices for immobilization of biomolecules or cations, inorganic membranes and support for catalysts ${ }^{3-6}$.

Silica polymers may be grown by hydrolysis and condensation reactions starting from silicon alkoxide such as tetraethylorthosilicate (TEOS) as a precursor. By controlling synthesis conditions carefully, the sol morphology can be directed towards weakly branched polymeric systems or to particulate systems ${ }^{7}$. Important process parameters are water content, the solvent, the catalyst used and its concentration and type of alkoxide used ${ }^{1,7,8}$. It is important that the effects of these parameters become well-understood in order to make sol-gel method a reliable and practical technology for industrial applications ${ }^{9}$.

A major concern in the production of monolithic dried gels is the prevention of cracks during aging and drying steps. As the solvent escapes from within the gel or as the pore size changes during these processes, stresses are introduced into the silica network, which may cause frac-

*e-mail: *rubia.lenza@ic.ac.uk, **wlv@ demet.ufmg.br Trabalho apresentado no $14^{\circ}$ CBECIMAT, Águas de São Pedro, Dezembro de 2000 . ture ${ }^{1,10,11}$. An approach to overcome this destructive action consists of the use of drying control chemical additives (DCCAs) which are incorporated in the starting mixture before gelation ${ }^{1,10,11}$. Formamide, a typical DCCA, have been found to reduce cracking, which helps to convert the wet gel into a monolithic xerogel within a reasonable time. It should be noted that the exact way in which the DCCAs improves the drying process is still unclear ${ }^{11}$.

Kinetic studies have been conducted in the wet state, i.e., before gelation or after gelation while the gel was still impregnated by liquid inside the pores. On the other hand, structural evaluations on silica gel monoliths or films have been performed on dried gels ${ }^{12}$. The influence of formamide on the sol to gel evolution was discussed in another paper $^{13}$. The purpose of the present study is to describe the structural evolution of silica gels with and without formamide and hydrofluoric acid. FTIR reflection spectra are presented for three different porous silica gels. The structure of the dried gels is discussed based on IR results, which provide some insight into structural features of these materials. Additional information on the gels network nanostructures was obtained using gas sorption analysis and density measurements.

\section{Experimental Procedure}

The preparation of the three types of silica sols is indicated in detail in Ref 13. The sols were prepared by 
hydrolysis and condensation of TEOS in presence of water and ethanol. Nitric acid was used as catalyst. The dried gels were heat treated in air at temperatures of $200{ }^{\circ} \mathrm{C}, 400{ }^{\circ} \mathrm{C}$, $600{ }^{\circ} \mathrm{C}, 800{ }^{\circ} \mathrm{C}, 1000{ }^{\circ} \mathrm{C}$ and $1050{ }^{\circ} \mathrm{C}$. The samples were maintained at the desired temperature during $1 \mathrm{~h}$. Sample A represents gel obtained without formamide, sample B is assigned to sol with DCCA and sample C corresponds to sol obtained with formamide and hydrofluoric acid.

After drying, the samples were analyzed by BET method, using an automatic gas sorption machine (Autosorb 1, Quantachrome, Co.) for specific volume, surface area, and sizes of pores within experimental error of $5 \%$. The average pore radius was estimated from $\mathrm{r}_{\mathrm{p}}=2 \mathrm{~V}_{\mathrm{p}} / \mathrm{S}_{\mathrm{p}}{ }^{3}$. True density (solid phase) measurements were performed using a helium micropycnometer (Quantachrome, Co.). Bulk densities were determined by mercury pycnometry. Both density measurements were performed on two samples and repeated six times. The performance of formamide in obtaining crack-free samples was evaluated by monolithicity measurements, which consist, in the present work, in the evaluation of the weight ratio of entire and crack-free samples to the total sample weight.

Diffuse reflectance FTIR (DRFTIR) spectra were recorded in a FTIR Paragon-1000 of Perkin Elmer Co., with a triglyceride sulfate detector, using diffuse reflectance accessory of Perkin-Elmer, Co. Spectra were collected with a $4 \mathrm{~cm}^{-1}$ resolution and 160 scans have been accumulated for each spectrum in the frequency range of $4400 \mathrm{~cm}^{-1}$ to $200 \mathrm{~cm}^{-1}$. Samples were grounded and diluted with $\mathrm{KBr}$ salt and were allowed to cool to room temperature in air before recording spectra. The signal/noise ratios are high in the diffuse reflectance spectra, so that the identification of the major features is unambiguous.

\section{Results and Discussion}

The spectra of the samples heat treated at several temperatures are given in Fig. 1. The silica gels spectra present several frequency regions:

A. $4000 \mathrm{~cm}^{-1}-3000 \mathrm{~cm}^{-1}$ : In this interval, the bands are mainly due to overtones or combinations of vibrations of $\mathrm{Si}-\mathrm{OH}$ or $\mathrm{H}_{2} \mathrm{O}^{12,14,15}$. The broad absorption band is generally composed of a superposition of the following stretching modes ${ }^{12,16,17}$ :

- $3740 \mathrm{~cm}^{-1}$ - corresponds to free $\mathrm{Si}-\mathrm{OH}$ groups on the surface of the gel;

- $3660 \mathrm{~cm}^{-1}$ - corresponds to pair of surface $\mathrm{Si}-\mathrm{OH}$ groups mutually linked by hydrogen bond or internal Si$\mathrm{OH}$ bonds;

- $3540 \mathrm{~cm}^{-1}$ - assigned to silanol groups linked to molecular water through hydrogen bonds;

- 3500 - $3000 \mathrm{~cm}^{-1}$ : corresponds to molecular water hydrogen bonded to each other and to $\mathrm{SiOH}$ groups.

B. $3000 \mathrm{~cm}^{-1}-1350 \mathrm{~cm}^{-1}$ : In this range, the bands are assigned to correspond to overtones and combinations of
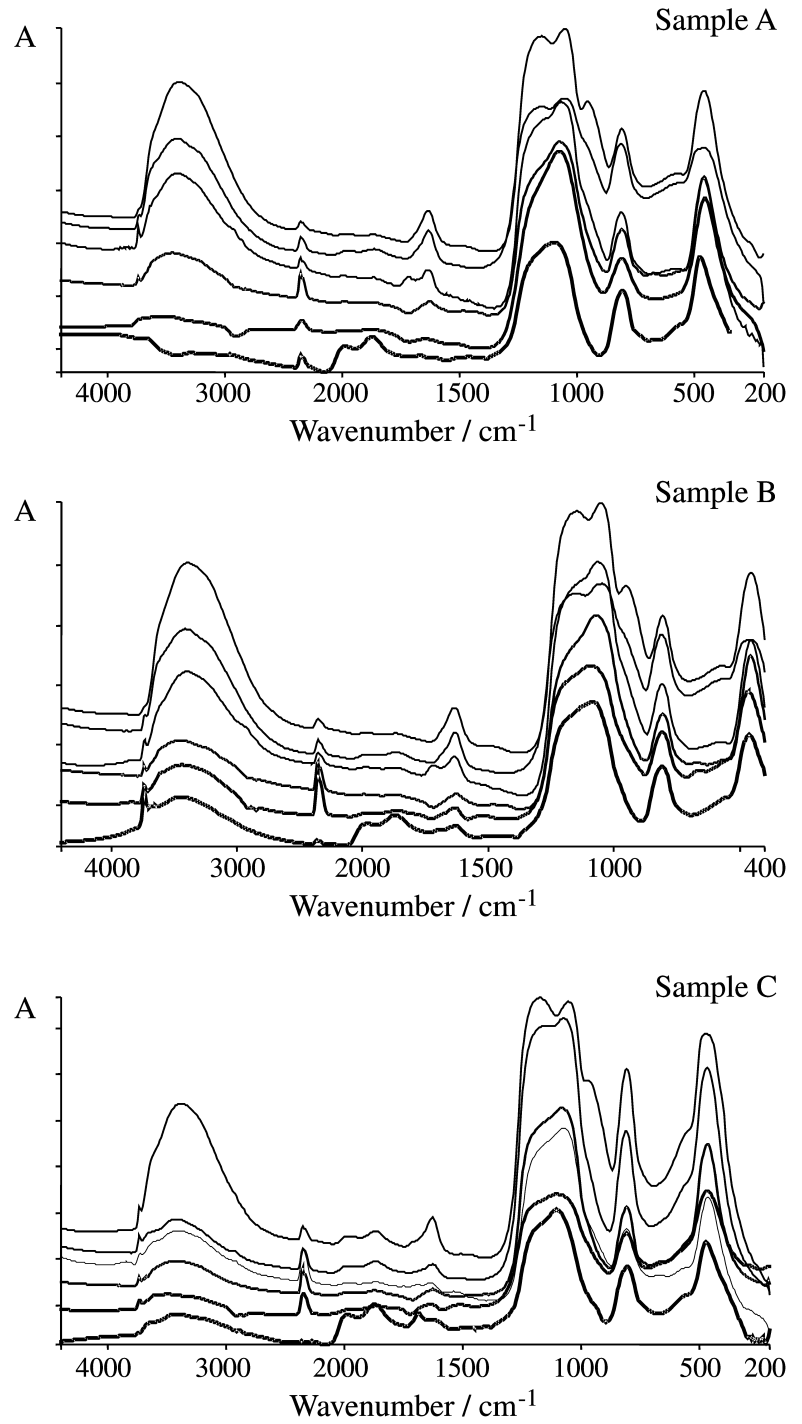

Figure 1. DRFTIR spectra of silica gels after heat treatment at different temperatures: $200{ }^{\circ} \mathrm{C}, 400{ }^{\circ} \mathrm{C}, 600{ }^{\circ} \mathrm{C}, 800{ }^{\circ} \mathrm{C}, 1000^{\circ} \mathrm{C}, 1050{ }^{\circ} \mathrm{C}$ (top to bottom). Absorbance in arbitrary units.

vibrations of organic residues, molecular water and $\mathrm{SiO}_{2}$ network $^{12,14-17}$.

- $2800 \mathrm{~cm}^{-1}$ - $3000 \mathrm{~cm}^{-1}$ - corresponds to the symmetric and asymmetric fundamental stretching vibrations of $\mathrm{CH}_{2}$ and $\mathrm{CH}_{3}$ groups belonging to alkoxide and solvent residues;

- $2350 \mathrm{~cm}^{-1}$ - assigned to atmospheric $\mathrm{CO}_{2}$;

- $1960 \mathrm{~cm}^{-1}, 1870 \mathrm{~cm}^{-1}, 1640 \mathrm{~cm}^{-1}$ - corresponds to combination of vibrations of the $\mathrm{SiO}_{2}$ network $\left(1640 \mathrm{~cm}^{-1}\right.$ band is often hidden by molecular water band);

- $1620 \mathrm{~cm}^{-1}$ - $1630 \mathrm{~cm}^{-1}$ - corresponds to vibrations of molecular water (dried gels obtained with formamide present also a shoulder around $1690 \mathrm{~cm}^{-1}$ that is characteristic of a $\mathrm{C}=\mathrm{O}$ band $^{12}$ );

- $1500 \mathrm{~cm}^{-1}-1350 \mathrm{~cm}^{-1}$ - assigned to vibrations of $\mathrm{CH}$ bonds. 
C. $1300 \mathrm{~cm}^{-1}-400 \mathrm{~cm}^{-1}$ : This region is associated with combinations of vibrations of silica network ${ }^{1,12,15,18-21}$ :

- $1260 \mathrm{~cm}^{-1}$ - $1000 \mathrm{~cm}^{-1}$ - corresponds to asymmetric stretching vibrations of Si-O-Si bridging sequences;

- $900 \mathrm{~cm}^{-1}$ - $980 \mathrm{~cm}^{-1}$ - assigned to stretching vibration of free silanol groups on the surface of the amorphous solid;

- $800 \mathrm{~cm}^{-1}$ - $820 \mathrm{~cm}^{-1}$ - corresponds to symmetric stretching vibrations of $\mathrm{Si}-\mathrm{O}-\mathrm{Si}$ bonds belonging to ring structures;

- $450 \mathrm{~cm}^{-1}$ - $460 \mathrm{~cm}-1$ - associated with Si-O-Si bond bending vibration.

It is clear that the effect of temperature is pronounced for all gels studied. As samples are heated to higher temperatures, intensity of absorption decreases on the low frequency side of the $\mathrm{OH}$ band $\left(2800 \mathrm{~cm}^{-1}-3600 \mathrm{~cm}^{-1}\right)$ and on the $1620 \mathrm{~cm}^{-1}-1630 \mathrm{~cm}^{-1}$ band and increases on the high frequency side $\left(3650 \mathrm{~cm}^{-1}-3750 \mathrm{~cm}^{-1}\right)$ of $\mathrm{OH}$ band. The $1620 \mathrm{~cm}^{-1}-1630 \mathrm{~cm}^{-1}$ band never completely disappears in a totally dried material, since, as mentioned before, a silica network absorption also occurs in that region ${ }^{17}$. The band associated with organic residues disappears at temperatures higher than $600{ }^{\circ} \mathrm{C}$ for all samples. It can be noted from Fig. 1 that in this temperature a new band appears around 1720 $\mathrm{cm}^{-1}$, which is characteristic of $\mathrm{C}=\mathrm{O}$ bond belonging to esters or acetates ${ }^{12}$. This is probably due to oxidation of alcohol or formamide residues.

In order to compare the spectra taken after various heat treatments and different samples, an internal standard is required. The band at $1870 \mathrm{~cm}^{-1}$ that corresponds to combination of vibrations of $\mathrm{SiO}_{2}$ is present in all spectra and is well resolved for the range of temperatures used in this work. In addition, the concentration of $\mathrm{SiO}_{2}$ is fairly constant during the heat treatments ${ }^{12}$. Thus, to compare the spectra, we used normalized intensity of absorption bands that is a ratio of the intensity of the desired band and the $1870 \mathrm{~cm}^{-1}$ band.

The decreasing in the intensity of the molecular water bands is shown in Fig. 2, which presents the normalized intensities of bands centered around $3400 \mathrm{~cm}^{-1}$ and $1630 \mathrm{~cm}^{-1}$ as a function of temperature. It can be noted by Fig. 2 that sample A has large content of adsorbed water and $\mathrm{OH}$ groups hydrogen bonded on its surface. On the other hand, samples B and C present high intensities of $3750 \mathrm{~cm}^{-1}$ band, as can be seen by Fig. 1, indicating a large amount of free silanol groups on its surface. The intensity of the $3750 \mathrm{~cm}^{-1}$ band increases when dehydration takes place, due to the conversion of some of the hydrogen bonded $\mathrm{SiOH}$ previously absorbing in the broad band centered at around $3400 \mathrm{~cm}^{-1}$ into free $\mathrm{SiOH}$ groups absorbing at $3750 \mathrm{~cm}^{-1}$. It can be noted from Fig. 1 that samples A and $\mathrm{C}$ do not present the free silanol band at $1050{ }^{\circ} \mathrm{C}$, whereas sample B still present this band at $1050{ }^{\circ} \mathrm{C}$. This fact indicates that sample $\mathrm{B}$ heat treated at temperatures as high as $1050^{\circ} \mathrm{C}$ has a surface covered by isolated silanol groups,

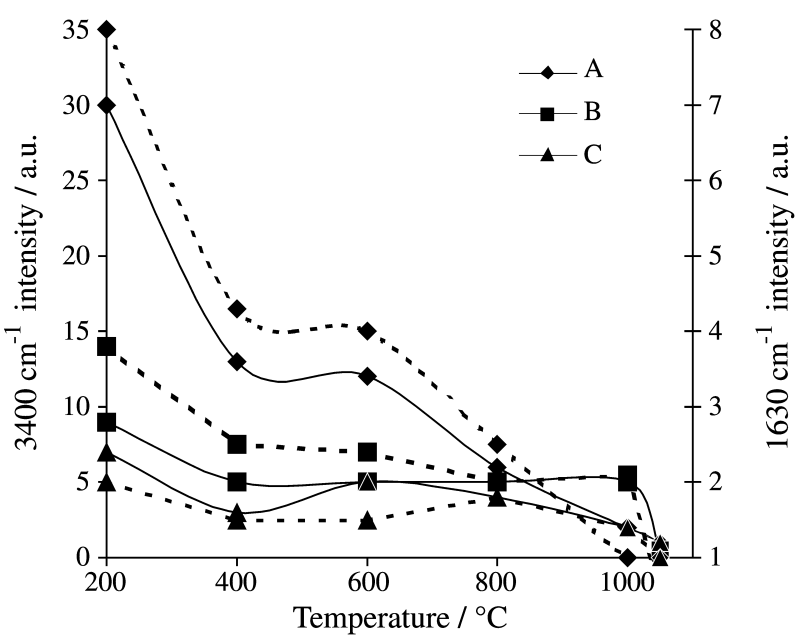

Figure 2. Variation of the normalized intensity of the $3400 \mathrm{~cm}^{-1}$ band $(-)$ and $1630 \mathrm{~cm}^{-1}$ band (---), showed in Fig. 1, as a function of temperature. The lines were drawn only as guide for the eyes.

which can not condense each other or hydrogen bond with atmospheric humidity. Sample A presents high quantity of internal silanols that absorb at $3650 \mathrm{~cm}^{-1}$. This can be attributed to the finer polymer type structure resulting from the more acidic reactions conditions ${ }^{12}$.

As shown in Fig. 1, for gels dried at $200{ }^{\circ} \mathrm{C}$, there are two dominant features around $1070 \mathrm{~cm}^{-1}$ and $1170 \mathrm{~cm}^{-1}$ (broad shoulder) that are assigned to asymmetric stretching vibrations of Si-O-Si in ASTO (transverse optical) and ASLO (longitudinal optical) modes, respectively, as they are observed in vitreous silica ${ }^{22}$. The corresponding symmetric motion is detected at around $810 \mathrm{~cm}^{-1}$. The band around $460 \mathrm{~cm}^{-1}$ is associated with Si-O-Si network bond bending vibration. The band centered around $960 \mathrm{~cm}^{-1}$, associated with the stretching mode Si-OH typical of gel structure, decreased in intensity and is insignificant when the material undergoes a polycondensation process during drying, as can be expressed by reaction ${ }^{1,17}$

$$
2(\mathrm{SiOH}) \rightarrow\left(-\mathrm{SiOSi}^{-}\right)+\mathrm{H}_{2} \mathrm{O}
$$

Figure 3 shows the ratio of intensity of $950 \mathrm{~cm}^{-1}$ band and $810 \mathrm{~cm}^{-1}$ band for all samples. It can be seen that the proportion of Si-O-Si bonds increases with temperature, indicating an underlying polycondensation process, whereby further Si-O-Si bonds are formed in the gel structure as a consequence of reaction $(1)^{21}$.

After drying, we noted changes also in the asymmetric stretching modes of $\mathrm{SiO}_{2}$, particularly in ASTO mode, for which the peak position is plotted in the Fig. 4 as a function of temperature. It can be seen that this peak shifts towards higher frequencies, indicating the strength of the network and the degree of connection in the membranes. The LO mode also shifts to higher frequencies with increasing temperature (not showed). The structure of vitreous silica 


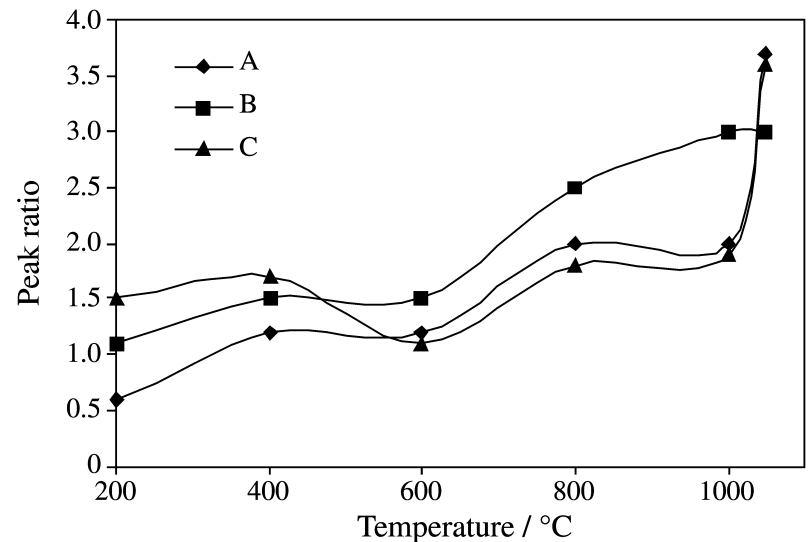

Figure 3. The ratio between the intensities of $950 \mathrm{~cm}^{-1}$ band and $810 \mathrm{~cm}^{-1}$ band, showed in Fig. 1, as a function of temperature.

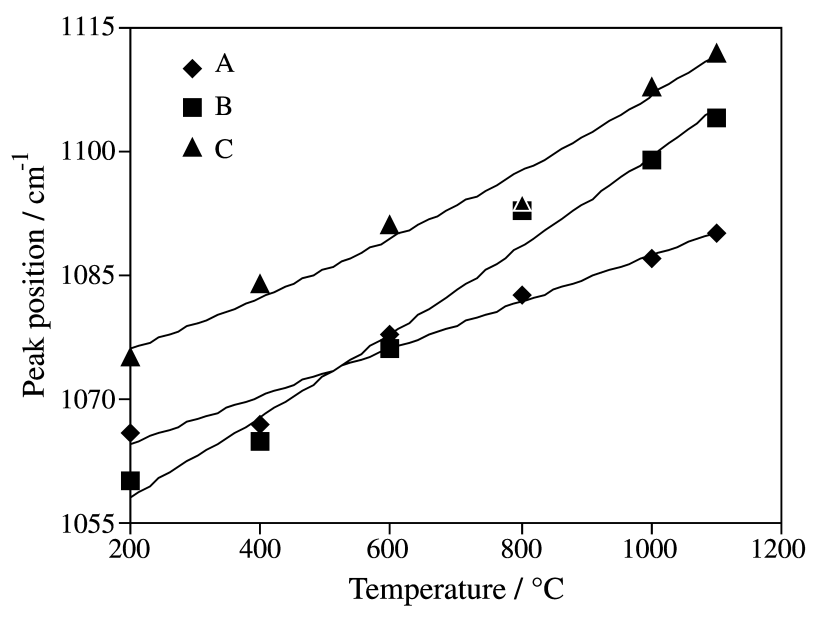

Figure 4. Asymmetric stretching mode of $\mathrm{SiO}_{2}$ (ASTO) peak position as a function of temperature. The lines were drawn only as guide for the eyes.

consists of an assembly of Si-O-Si rings of various sizes in which each Si-O-Si belongs to a cyclic structure ${ }^{22}$. For samples containing formamide the $\mathrm{Si}-\mathrm{O}-\mathrm{Si}$ band reach higher frequencies, particularly for gel C. A shift in the ASTO mode to higher frequencies reveals the extent of the molecular structural change. The IR spectrum must be made up from contributions (additively) of various silica structures (both rings and chains) in the material. As the temperature increases, there is a larger intratetrahedral bond angle, a stronger $\mathrm{Si}-\mathrm{O}$ bond strength, and a shorter bond length. This could be explained by the loss of smaller ring sizes or small chains as densification occurs ${ }^{23}$. The resulting shifts in the peak, corresponding to maximum position of the ASTO mode of the samples studied, are equal to $24 \mathrm{~cm}^{-1}$ for sample A, $44 \mathrm{~cm}^{-1}$ for sample B and 37 $\mathrm{cm}^{-1}$ for sample C, from $200{ }^{\circ} \mathrm{C}$ to $1050^{\circ} \mathrm{C}$. Sample C reach the higher frequency of TO mode, c.a. $1112 \mathrm{~cm}^{-1}$, sample $B$ reach the value of $1104 \mathrm{~cm}^{-1}$ and sample $A$, the value of $1090 \mathrm{~cm}^{-1}$. The value of frequency of TO mode for a vitreous silica is $\sim 1122 \mathrm{~cm}^{-1}-1125 \mathrm{~cm}^{-115}$. This means that the samples dried at $1050{ }^{\circ} \mathrm{C}$ did not achieve full density. We concluded that in the presence of formamide and HF, the gels network are stronger and have a more cross-linked structure with less smaller rings or chains ${ }^{23}$.

The changes in the frequency of Si-O-Si ASTO mode can be correlated with physical properties such as refractive index, micro hardness and density ${ }^{17}$. Figure 5 shows the relation between TO mode peak position and true density. It can be noted that de ASTO peak position increases with the sample densification.

Figure 6 shows the nitrogen adsorption-desorption isotherms for the different samples. According to the original BDDT classification ${ }^{24}$, the isotherms obtained for sample A at $400{ }^{\circ} \mathrm{C}$, is of type I, being characteristic of a microporous solid (pore radii $<1.5 \mathrm{~nm}$ ). A high volume is absorbed at the lowest relative pressure, which indicates a large volume of very small pores. The virtual lack of hysteresis in the desorption branch is generally interpreted to mean that the pores are smooth and cylindrical ${ }^{1,25}$. The isotherm for the other samples is a type IV isotherm ${ }^{23}$. A characteristic feature of type IV isotherm is the hysteresis that is normally attributed to the presence of pore cavities larger in diameter than the openings (throats) leading into them, forming the so-called ink-bottle pores ${ }^{1,25}$. Compared to the isotherm of sample A, less gas is adsorbed at low relative pressures and a sudden increase in adsorption occurs at high pressure, indicating that only mesopores are present ${ }^{1}$.

Physical properties such as specific surface area $\left(\mathrm{S}_{\mathrm{p}}\right)$, specific pore volume $\left(V_{p}\right)$ and average pore radius $\left(r_{p}\right)$ for the silica gels as a function of temperature are listed in Table 1. Bulk densities $\left(\rho_{\mathrm{b}}\right)$ varied from $1.14 \mathrm{~g} / \mathrm{cm}^{3}$ at $200{ }^{\circ} \mathrm{C}$ to $1.60 \mathrm{~g} / \mathrm{cm}^{3}$ at $1050{ }^{\circ} \mathrm{C}$, for sample A. For sample B, $\rho_{b}$ varied from $0.67 \mathrm{~g} / \mathrm{cm}^{3}$ to $0.88 \mathrm{~g} / \mathrm{cm}^{3}$ and for sample $\mathrm{C}$, from $0.77 \mathrm{~g} / \mathrm{cm}^{3}$ to $1.17 \mathrm{~g} / \mathrm{cm}^{3}$. It can be seen from Table 1 that the samples obtained without formamide have finer pore structures, with larger microporous area and high bulk

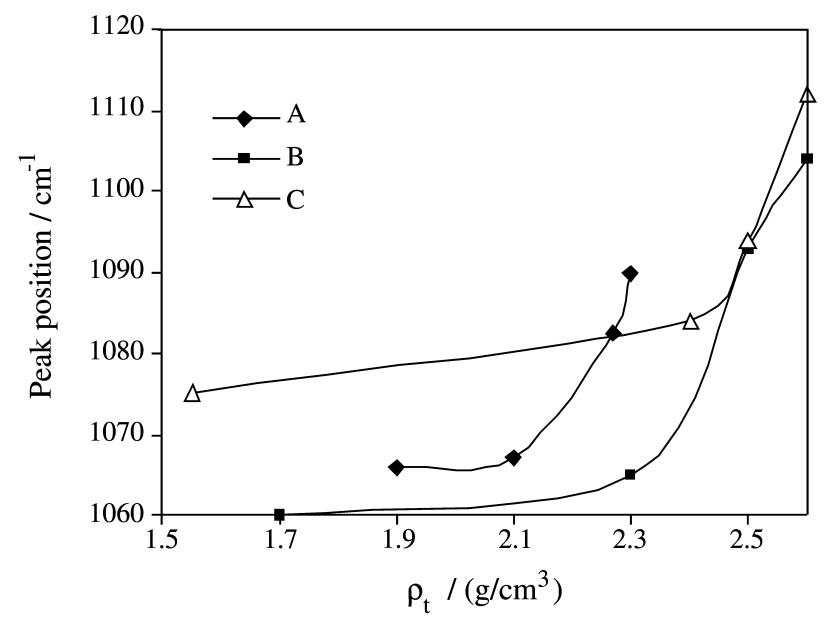

Figure 5. Asymmetric stretching mode of $\mathrm{SiO}_{2}$ (ASTO) peak position as a function of true density. 
Table 1. Structural properties of silica membranes.

\begin{tabular}{|c|c|c|c|c|c|c|c|c|c|}
\hline \multirow[t]{2}{*}{ Temperature $\left({ }^{\circ} \mathrm{C}\right)$} & \multicolumn{3}{|c|}{$\mathrm{S}_{\mathrm{p}}\left(\mathrm{m}^{2} / \mathrm{g}\right)$} & \multicolumn{3}{|c|}{$\mathrm{V}_{\mathrm{p}}\left(\mathrm{cm}^{3} / \mathrm{g}\right)$} & \multicolumn{3}{|c|}{$\mathrm{r}_{\mathrm{p}}(\mathrm{nm})$} \\
\hline & $\mathrm{A}$ & $\mathrm{B}$ & $\mathrm{C}$ & $\mathrm{A}$ & $\mathrm{B}$ & $\mathrm{C}$ & A & $\mathrm{B}$ & $\mathrm{C}$ \\
\hline 200 & 279 & 419 & 279 & 0.15 & 0.23 & 0.84 & 1.1 & 1.1 & 1.5 \\
\hline 400 & 695 & 465 & 695 & 0.42 & 1.13 & 1.15 & 1.2 & 4.9 & 2.0 \\
\hline 800 & 463 & 450 & 463 & 0.28 & 1.14 & 1.6 & 1.2 & 5.0 & 1.5 \\
\hline 1050 & 1 & 350 & 1 & 0.06 & 0.65 & 0.05 & 7.5 & 4.1 & 8.1 \\
\hline
\end{tabular}

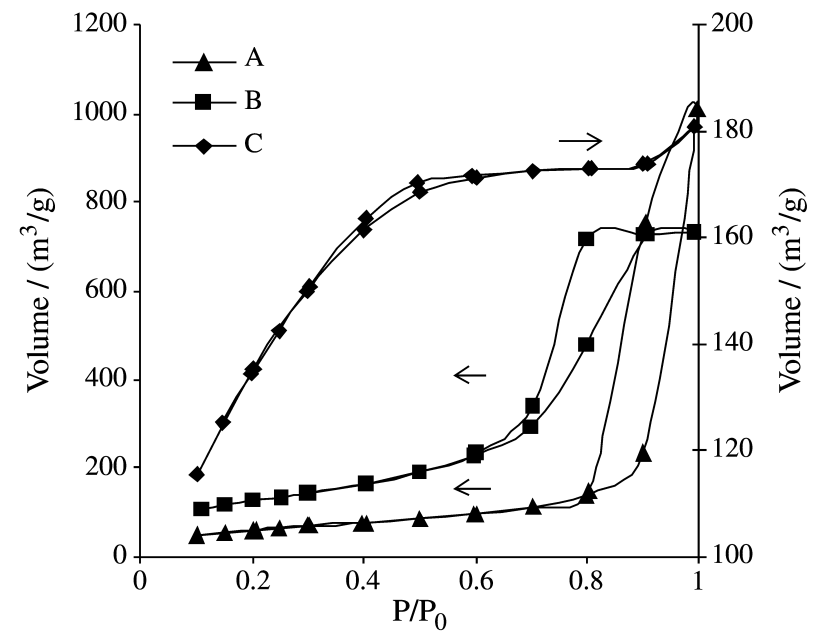

Figure 6. Nitrogen adsorption-desorption for degassed silica gels.

densities than the samples with DCCA, which present only mesoporosity. The coarser structure of samples B and C can be a result of the high $\mathrm{pH}$ produced by hydrolysis of formamide during the polycondensation process ${ }^{1,13}$. As the temperature increases, the surface area and pore volume decrease, whereas the pore size remains roughly constant until $800^{\circ} \mathrm{C}$. At high temperatures it is observed a coarsening of the pores for samples $\mathrm{A}$ and $\mathrm{C}$. It can be noted from Table 1 that at $1050{ }^{\circ} \mathrm{C}$ the sample $\mathrm{B}$ has a high surface area, c.a. $350 \mathrm{~m}^{2} / \mathrm{g}$ and pore volume, c.a. $0.65 \mathrm{~cm}^{3} / \mathrm{g}$, whereas the samples $\mathrm{A}$ and $\mathrm{C}$ are denser. Concerning the use of sol-gel materials for catalytic and separation process, sample B seems to be the best choice, since it presents elevated surface area and porosity at high temperatures, where the gels are stable and do not crack under exposure to liquids or atmospheric humidity. It can be also noted that the presence of HF introduces a different structural arrangement of the pore structure, which probably is due to the action of fluoride ions ${ }^{1}$.

Sample A present low value of monolithicity, c.a. of $50 \%$, samples B and C present higher values of monolithicity, $100 \%$ and $90 \%$, respectively. The fracture process is linked with the occurrence of differential stresses produced by capillary forces in the pores of the drying gel. The emptying of the interstitial liquid is accompanied by formation of a gel-liquid interface, which generates local pressure increments $\Delta \mathrm{P}$, which is inversely proportional to pore size. Thus, small pore sizes, typical of gels obtained in acid medium $(\mathrm{r} \sim 1-10 \mathrm{~nm}$ ) generate considerable $\Delta \mathrm{P}$ (about 4-15 $\mathrm{MPa})^{11}$. Differences between local $\Delta \mathrm{P}$ values may produce cracks when the cohesive resistance of the drying solid is overstepped ${ }^{1,11}$. The creation of new bridging bonds by reaction (1) stiffens and strengthens the gel network. The amount of shrinkage that occurs during drying is dependent on the stiffness of the gel network. If the gel is aged under conditions of high solubility, the network may resist compression by capillary forces during drying, which is obtained for membranes with formamide. Sample A presents larger linear shrinkage for drying between $200^{\circ} \mathrm{C}$ and 1050 ${ }^{\circ} \mathrm{C}($ c.a. $7 \%$ ) than samples $\mathrm{B}$ and $\mathrm{C}$, for which the shrinkages are $2 \%$ and $1.7 \%$, respectively. The samples obtained with DCCA have coarse pore structures without microporosity, as described above, and all these features help reducing crack formation. Since shrinkage and cracking are produced by capillary forces, coarser and stronger networks obtained with formamide presents smaller shrinkage and high monolithicity.

\section{Conclusion}

DRFTIR is a useful tool to follow structural changes that occur at the surface and in the network of silica gels obtained via sol-gel process. For samples obtained without formamide, more internal silanol groups are retained in the silica network. On the other hand, for samples obtained with DCCA, water is removed more easily and less internal silanols remain in the samples. Gels obtained only with formamide presents large amount of isolated silanol groups on its surface, which gives rise to a more active surface.

FTIR spectra yield important information on the compactness of the silica network. A high frequency of the asymmetric $\mathrm{Si}-\mathrm{O}-\mathrm{Si}$ stretching vibration indicates a strongly cross-linked framework, which is found in samples obtained with formamide. Lower frequencies of the asymmetric Si-O-Si stretching vibration are observed in the spectra of weakly cross-linked sample made without formamide.

Silica gels obtained with formamide present smaller values of shrinkage and higher monolithicity than gels obtained without this additive. In the absence of for- 
mamide, the gel structure is poorly interconnected and presents characteristic microporosity, whereas gels obtained with formamide have a mesoporous structure.

\section{Acknowledgements}

The authors thank the financial support by CAPES and CNPq.

\section{References}

1. Brinker, C.J.; Scherer, G.W. Sol-Gel Science: The Physics and Chemistry of Sol-Gel Processing, Academic Press, inc. San Diego, CA. P. 907, 1990.

2. Damrau, U.; Marsmann, H.C. Journal of Non-Crystalline Solids, v. 168, p. 42, 1994.

3. Lenza, R.F.S.; Vasconcelos, W.L. Journal of NonCrystalline Solids, v. 273, n. 1-3, p. 164, 2000.

4. Mansur, H.S.; Oréfice, R.L.; Vasconcelos, W.L.; Lenza, R.F.S.; Lobato, Z. Journal of Non-Crystalline Solids, v.273, n. 1-3, p. 109, 2000.

5. Raman, N.K.; Ward, T.L.; Brinker, C.J.; Sehgal, R.; Smith, D.M.; Duan, Z.; Hampden-Smith, M. Apllied Catalysis A General, v. 69, p. 65, 1993.

6. Siemisnka, L.; Ferguson, M.; Zerda, T.W.; Couch, E. Journal of Sol-Gel Science and Technology, v. 8, p. 471, 1997.

7. deLange, R.S.A.; Hehhink, J.H.A.; Kelzer, K.; Burggraaf, A.J. Journal of Non-Crystalline Solids, v. 191, p. 1, 1995.

8. Nair, B.N.; Elferink, J.W.; Keizer, K.; Vermeij, H. Journal of Sol-Gel Science and Technology, v. 8, p. 471, 1997.

9. Fardad, M.A.; Yeatman, E.M.; Dawnay, E.J.C.; Green, M.; Horowitz, F. Journal of Non-Crystalline Solids, v. 183, p. 260, 1995.
10. Orcel, G.; Hench, L.L.; Artaki, I.; Jonas, J.; Zerda, T.W. Journal of Non-Crystalline Solids, v. 105, p. 223, 1988.

11. De La Rosa Fox, N.; Esquivias, L. Journal of Material Science Letters, v. 10, p. 1237, 1991.

12. Orcel, G.; Phalippou, J.; Hench, L.L. Journal of NonCrystalline Solids, v. 88, p. 114, 1986.

13. Lenza, R.F.S.; Vasconcelos, W.L. Materials Research, in press.

14. Bartholomeu, R.F.; Butler, B.L.; Hoover, H.L.; Wu, C.K. Journal of the American Ceramic Society, v. 63, n. 9-10, p. 481, 1980.

15. Almeida, R.M.; Pantano, C.G. Journal of Applied Physics, v. 68, n. 8, p. 4225, 1990.

16. McDonald, R.S. Journal of American Chemical Society, v. 62, p. 1168, 1958.

17. Wood, D.L.; Rabinovich, E.M.; Johnson, D.W.; MacChesney, J.B.; Vogel, E.M. Journal of the American Ceramic Society, v. 66, n. 10, p. 693, 1983.

18. Schraml-Marth, M.; Walther, K.L.; Wokan, A.; Handy, B.E.; Baiker, A. Journal of Non-Crystalline Solids, v.143, p.93, 1992.

19. Chmel, A.; Mazurina, E.K.; Shashkin, V.S. Journal of Non-Crystalline Solids, v. 122, p. 285, 1990.

20. Parril, T.M. Journal of Material Research. v. 9, n. 3, p. 723, 1994.

21. Bertoluzza, A.; Fagnano, C.; Morelli, M.A. Journal of Non-Crystalline Solids, v. 22, p. 285, 1982.

22. Viart, N.; Niznansky, D.; Rehspringer, J.L. Journal of Sol-Gel Science and Technology, v. 8, p. 183, 1997.

23. Taipau, C.; West, J.K.; Hench, L.L. Better Ceramics Through Chemistry VI, v. 346, p. 727, 1994.

24. Brunauer, S.; Deming, L.S.; Deming, W.S.; Teller, E. Journal of the American Ceramic Society, v. 62, p. 1723,1940 .

25. Lowell, S.; Shields, J.S. Powder Surface Area and Porosity, 3rd ed., Chapman and Hall, London, 1991. 